\title{
As Conseqüências Comportamentais da Insatisfação dos Clientes
}

\section{The Behavioral Consequences of the Customer Dissatisfaction}

\author{
Daniel Von der Heyde Fernandes * \\ Mestrando em Marketing pela PPGA/EA/UFRGS, Porto Alegre/RS, Brasil. \\ Cristiane Pizzutti dos Santos \\ Doutora em Administração pela PPGA/EA/UFRGS. \\ Professora de Marketing na EA/UFRGS, Porto Alegre/RS, Brasil.
}

*Endereço: Rua Washington Luis, 855, Porto Alegre/RS, 90010-460. E-mail:dvon@terra.com.br 


\title{
ResUMo
}

O propósito deste estudo é investigar os antecedentes das intenções comportamentais de clientes insatisfeitos. Inicialmente, revisam-se os fundamentos teóricos. A seguir, apresentam-se a metodologia empregada e as três etapas de pesquisa realizadas. $\mathrm{Na}$ primeira, qualitativa, foram realizadas 16 entrevistas em profundidade, que deram origem ao instrumento de coleta de dados. Na segunda, a eficácia da manipulação da variável a ser controlada na pesquisa experimental - nível de insatisfação - foi qualitativamente validada com 22 entrevistados. Finalmente, um questionário estruturado foi aplicado a 480 estudantes de graduação. Os resultados mostram que o impacto do nível de insatisfação nas intenções de comunicação boca-a-boca negativa e troca de empresa é alto. Em relação à intenção de reclamação, o impacto da autoconfiança do consumidor é superior à influência das demais variáveis. A atitude em face da reclamação exerceu papel de moderadora entre o nível de insatisfação e a intenção de reclamação. Esses resultados fornecem implicações acadêmicas e gerenciais para minimizar a troca de fornecedor e a comunicação negativa e aumentar os índices de reclamação e, portanto, as oportunidades de remediar problemas.

Palavras-chave: insatisfação; reclamações; comunicação boca-a-boca negativa; troca de fornecedor.

\begin{abstract}
The purpose of this study is to investigate the antecedents of the behavioral intentions of dissatisfied customers. Initially, the theoretical foundations are revised. After that, the methodology employed and the three research phases are presented. In the first, a qualitative one, 16 in depht interviews were made and gave origin to the instrument for data collection. In the second phase, the manipulation effectiveness of the controlled variable in the experimental research - dissatisfaction level - was qualitatively validated with 22 interviews. Finally, the questionnaire was applied to 480 undergraduate students. The results show that the impact of dissatisfaction level on the negative word-of-mouth communication and switch company intentions are high. In regarding to the complaint toward the company intention, the impact of the consumer's self-confidence is superior to the influence of the other variables. Attitude towards the act of complaining moderates the relationship between dissatisfaction intensity and complaint intention. These results supply academic and managerial implications to minimize the customer intentions to switch provider and to exert negative word-of-mouth communication and to increase the number of complaints and, therefore, the opportunities to remedy customers' problems.
\end{abstract}

Key words: dissatisfaction; complaints; negative word-of-mouth communication; switching of provider. 


\section{INTRODUÇÃO}

Após uma experiência insatisfatória, o consumidor pode, como conseqüência do descontentamento, realizar diversas ações, como, por exemplo: mudar de marca ou fornecedor (exit), reclamar aos revendedores e/ou fabricantes, comunicar a experiência negativa que teve a amigos e parentes (boca-a-boca negativa), recorrer a agências e órgãos de proteção ao consumidor e, até mesmo, não fazer nada. Entender as consequiências da insatisfação dos clientes e o que influencia cada uma delas são questões críticas para gerenciar efetivamente processos de póscompra, reter os clientes atuais, desenvolver relacionamentos de longo prazo e minimizar os efeitos da comunicação boca-a-boca negativa.

De acordo com Blodgett e Anderson (2000), embora pesquisas anteriores tenham aumentado o entendimento sobre o comportamento de insatisfação, a maioria dos estudos tem focado apenas nos clientes que registraram seu descontentamento. Dados empíricos mostram que cerca de dois terços dos clientes não reportam sua insatisfação à empresa (Andreasen, 1984; Richins, 1983). Outros estudos evidenciaram que apenas um em cada vinte clientes insatisfeitos reclama (Technical Assistance Research Program [TARP], 1986). Apesar da disparidade, os estudos reportam que a maior parte dos clientes insatisfeitos simplesmente omite esse fato à empresa. A maioria, entretanto, troca de forma silenciosa de fornecedor e/ou realiza comunicação boca-a-boca negativa (Richins, 1983; Singh, 1988). Não obstante, muitas empresas utilizam as taxas de reclamação como indicadores de insatisfação, realizando, dessa forma, um erro estratégico. No caso dos supermercados brasileiros, por exemplo, somente $4 \%$ dos clientes insatisfeitos reclamam, e 75\% não reclamam e não voltam a comprar na loja (50 anos de supermercado no Brasil, 2002).

Um cliente insatisfeito que não reclama à empresa gera uma série de inconvenientes. Primeiro, a empresa perde a oportunidade de remediar o problema e reter o cliente (Hirschman, 1970). Segundo, a reputação da firma pode ser danificada por comunicação boca-a-boca negativa realizada por clientes insatisfeitos (Richins, 1983), resultando em perda de clientes potenciais e correntes. Terceiro, a organização é privada de informações valiosíssimas sobre a qualidade de seus produtos e serviços (Fornell \& Wernerfelt, 1987), impedindo a oportunidade de rever seu processo e realizar melhorias. Esses inconvenientes parecem ser agravados em mercados altamente competitivos, nos quais as empresas precisam reter clientes e desenvolver relacionamentos duradouros para obter sustentação de longo prazo. 
Apesar da importância estratégica do entendimento das reações dos consumidores à insatisfação, o conhecimento no assunto ainda parece limitado. Os estudos das reações da insatisfação ofereceram uma taxonomia (Singh, 1988) e uma tipologia (Singh, 1990) de resposta à insatisfação válida e consistente e têm identificado diversos determinantes do comportamento pós-insatisfação (e.g, Bearden, 1983; Kim, Kim, Im, \& Shin, 2003; Singh, 1990; Singh \& Wilkes, 1996; Voorhees \& Brady, 2005), que instigam e sustentam avanços (na teoria) sobre o tema. Entretanto a literatura no assunto é fragmentada, já que poucos trabalhos consideram mais de um determinante em conjunto ou realizam comparações de seus impactos. Além disso, apesar de estudos consistentes terem encontrado resultados expressivos pela abordagem da personalidade (Gronhaug \& Zaltman, 1981; Singh, 1990), poucos trabalhos empíricos incluem esses antecedentes. Por fim, a maioria dos estudos tem focado nos consumidores que registram a reclamação, embora boa parte dos clientes simplesmente fala mal da empresa a conhecidos ou silenciosamente troca de fornecedor. Tais inconsistências têm freado o desenvolvimento sistemático e cumulativo de estudos nesta área.

Este trabalho pretende ajudar a preencher essas lacunas. Primeiro, examinamse as atitudes, percepções e intenções de clientes insatisfeitos, sejam eles reclamantes ou não. Segundo, as respostas da insatisfação são avaliadas por múltiplas intenções de ação: reclamação à empresa, boca-a-boca negativa e troca de fornecedor. Terceiro, comparam-se os impactos dos antecedentes do comportamento pós-insatisfação trazidos pela literatura. Essas informações são válidas para entender melhor quando, como e por que os clientes insatisfeitos reagem ao problema. O presente artigo constitui-se de três partes principais. A primeira revela a fundamentação teórica utilizada, enfatizando a literatura sobre o comportamento pós-insatisfação e o modelo teórico a ser testado. A segunda parte discute aspectos relacionados à metodologia de pesquisa, e a terceira parte apresenta os principais resultados encontrados.

\section{Revisão de literatura e Hipóteses}

\section{A Insatisfação do Consumidor}

Insatisfação pode ser entendida como "uma emoção negativa gerada pela desconfirmação de expectativas na experiência de consumo" (Day, 1984, p. 497). Oliver (1999) acrescenta que "a insatisfação é o tendão de Aquiles da lealdade" (p. 37), por seu papel eminente no rompimento de relacionamentos entre clientes e empresa. 
O estudo da insatisfação é, de certa forma, recente. Antes da década de 70, pouco havia sido publicado na literatura de marketing sobre insatisfação dos consumidores. A partir dessa data, porém, parte em resposta ao consumismo ${ }^{(1)}$, o interesse no tema cresceu rapidamente. Como resultado, pesquisadores começaram a analisar não apenas a satisfação, mas a insatisfação e como e por que os consumidores respondem a ela. Com base nisso, reconheceu-se que a insatisfação e as respostas dos consumidores a ela têm implicações significativas para fenômenos importantes no marketing, como intenção de recompra (Day, 1984; TARP, 1986), confiança (Bitner, Booms, \& Tetreault, 1990; Tax, Brown, \& Chandrashekaran, 1998) e feedback do mercado e desenvolvimento de novos produtos (Fornell \& Wernerfelt, 1987).

Os primeiros estudos sobre o tema consideraram a insatisfação como extremo contrário à satisfação em uma mesma escala. Segundo Evrard (1993), a satisfação pode ser vista como um continuum unidimensional entre dois pólos opostos: satisfação e insatisfação. Maddox (1981) foi o pioneiro na ampliação desse conceito ao criar a two-factor theory (teoria dos dois fatores), em que propõe que a satisfação e a insatisfação são conceitos diferentes, uma vez que não estão diretamente relacionados. O autor indica que os níveis de satisfação e insatisfação são independentes, utilizando-se, para explicá-los, a metodologia do incidente crítico. Mittal e Lassar (1998) corroboram a diferenciação entre insatisfação e satisfação, ao verificar a influência assimétrica dos construtos, pois o impacto dos desempenhos negativos sobre a satisfação geral dos consumidores é bem maior do que o impacto dos desempenhos positivos. Recentemente, Babin e Griffin (1998) testaram e validaram um modelo de medidas, considerando a satisfação e a insatisfação como construtos separados. Os autores encontraram correlação significativa entre os construtos; entretanto "um modelo com a satisfação e a insatisfação em dois fatores, representando dois construtos latentes distintos provê índices de ajustamento bastante superiores ao modelo com um único construto de satisfação e insatisfação" (p. 133). De acordo com esses argumentos e com a maioria dos pesquisadores, pode ser inferido que a insatisfação do cliente é um construto separado da satisfação.

\section{As Ações Pós-insatisfação do Consumidor}

As ações dos clientes em face de experiências insatisfatórias de consumo foram estudadas inicialmente por Hirschman (1970). Ele argumentou existirem três possíveis respostas à insatisfação: abandono (exit), vocalização (voice) e lealdade (loyalty). Lealdade significaria a não tomada de ação e permanecer com a empresa, mesmo após a ocorrência do problema. Abandono seria não realizar compras novamente com a empresa; e resposta por vocalização significaria a tentativa de obter retorno do fabricante ou varejista. Mais tarde, estudos sugeriram 
que essa conceitualização seria muito simplista; e uma nova forma de expressar as ações dos clientes foi proposta por Day e Landon (1977), que dividem as ações pós-insatisfação em privadas e públicas. Ações públicas incluem buscar compensação da própria empresa ou fabricante, reclamar a órgãos competentes e tomar ações legais. Ações privadas incluem parar de comprar ou boicotar a loja que provocou a insatisfação e avisar amigos, família e conhecidos sobre a insatisfação.

O trabalho de Singh (1988) sugere que as respostas dos clientes à insatisfação podem ser categorizadas em três grupos: 1) respostas por vocalização, incluindo a reclamação direta à empresa e nenhuma resposta, apenas a recompra; 2) respostas privadas, isto é, ações que envolvem comunicação boca-a-boca negativa a amigos e parentes e parar de comprar e trocar de fornecedor; e 3) respostas à terceira parte, incluindo ações junto a agências externas e ações legais. Um ponto importante é que estas ações não são mutuamente excludentes, isto é, as pessoas podem responder à insatisfação por meio do engajamento em múltiplas ações, por exemplo, reclamar à loja que vendeu o produto, falar a amigos sobre sua experiência e nunca mais voltar ao estabelecimento. Seguindo esta lógica, Singh (1989) argumenta que o comportamento pós-insatisfação ${ }^{(2)}$ deve ser definido como um "conjunto de múltiplas respostas (comportamentais ou não), algumas ou todas geradas por uma insatisfação percebida com um episódio de compra" (p. 84). A classificação desenvolvida por Singh (1988) parece ser suficientemente refinada, além da mais representativa e aceita até os dias de hoje. Utilizaram-se, no presente trabalho, os itens da taxonomia de Singh (1988), com exceção daqueles itens que medem as intenções de resposta à terceira parte. A exclusão desses itens obedeceu aos resultados da fase qualitativa e vai ao encontro dos trabalhos de Chauvel (2000) e de Giglio e Chauvel (2002) sobre insatisfação do consumidor brasileiro, nos quais a opção de resposta à terceira parte, via reclamação ao Procon e judicial, foi desconsiderada pelos consumidores.

Por parte das empresas, o descontentamento do cliente é diagnosticado por meio do registro da reclamação, a qual possui diversas formas de entrada. Nyer (2000) sugere que encorajar clientes insatisfeitos a expressar seus sentimentos e opiniões pode causar aumento de satisfação. Isso é coerente com os achados dos estudos do TARP (1986), que reportaram que, mesmo quando as reclamações não foram resolvidas adequadamente, os clientes que registraram uma reclamação experimentaram maiores níveis de intenção de recompra comparados àqueles que não reclamaram. Entretanto o uso de vias para atendimento a reclamações tem, na prática, pouco valor, se não oferece um retorno efetivo ao cliente (Fornell \& Wernerfelt, 1987). Encorajar a reclamação é percebido como fraudulento, se o consumidor não receber uma resposta positiva da empresa (Goodwin \& Ross, 1990). 
A troca de fornecedor inclui tanto os consumidores que preferem a forma passiva, de não fazer nada e permanecer com o fornecedor, quanto aqueles que agem de forma ativa em face do problema e trocam de empresa fornecedora (Bearden \& Oliver, 1985). Entretanto a saída do cliente pode ser parcial, ou seja, ao encontrar alguma alternativa razoável, o cliente pode considerar outros fornecedores para compra, sem descartar o atual (Reichheld, 1996).

O comportamento de boca-a-boca negativa é, segundo Day e Landon (1977), componente da dimensão privada de respostas à insatisfação. O estudo do programa TARP (1986) mostra que um cliente insatisfeito divulga, em média, para outras nove pessoas sua experiência negativa e que as empresas perdem de dez a quinze por cento do seu volume anual de vendas por causa de serviços malfeitos prestados. A comunicação boca-a-boca é fenômeno importante, em que os consumidores recebem informações relacionadas a organizações e a suas ofertas. Devido à comunicação boca-a-boca ser independente da empresa em questão, ocorrer através de fontes que os consumidores consideram confiáveis, como os amigos e prover informações referentes ao desempenho do produto e às conseqüências sociais e psicológicas de uma decisão de compra (Richins, 1983), sua influência nas avaliações dos consumidores é maior do que a influência das informações recebidas por fontes comerciais (Herr, Kardes, \& Kim, 1991).

\section{Fatores Influenciadores das Respostas Pós-insatisfação}

A idéia de incluir a intensidade da insatisfação como predecessor das respostas dos clientes a ela não é nova. Os primeiros modelos, incluindo tal relação, foram desenvolvidos por Landon (1977). Segundo Richins (1983), as respostas para insatisfação podem ser ordenadas pelo nível de esforço envolvido que, por sua vez, é dependente da seriedade da insatisfação. Desta forma, quanto menor a seriedade, menor o esforço e maior a tendência a não fazer nada. Estudos mais recentes, como o de Maute e Forrester (1993), concluíram que a magnitude da insatisfação aparece como forte antecedente do comportamento de reclamação. Assim, as primeiras hipóteses geradas são:

H1: O nível de insatisfação terá impacto positivo na intenção de reclamação à empresa.

H2: O nível de insatisfação terá impacto positivo na intenção de boca-a-boca negativa.

H3: O nível de insatisfação terá impacto positivo na intenção de troca de fornecedor.

As variáveis de personalidade também aparecem como úteis à investigação de 
um modelo de resposta à insatisfação dos clientes. Em geral, os clientes que reclamam tendem a ter mais experiências anteriores de reclamação, atitudes mais elevadas em face da reclamação, maior conhecimento dos direitos do consumidor e a serem mais assertivos (Richins, 1983; Singh, 1990). O papel dessas variáveis é explicado por meio das teorias do aprendizado e da personalidade. O modelo de aprendizado defende que o comportamento pósinsatisfação é função de aprendizado anterior (p.ex., conhecimento de práticas injustas, informação sobre os direitos do consumidor e canais de reclamação), o qual auxilia na formação de atitudes, que em resposta determina o comportamento (Landon, 1977).

A atitude é definida como o estado mental usado pelo indivíduo para estruturar a forma pela qual ele percebe seu ambiente e orienta seu estilo de resposta a estímulos exteriores (Kim et al., 2003). A atitude perante a reclamação é, portanto, construída pelo acúmulo de experiências de reclamação do sujeito e representa o julgamento, em termos da polaridade favorável/desfavorável à ação de reclamação (Singh, 1989). Segundo Singh (1990), essa variável teria duas dimensões. A primeira - Normas Pessoais - é formada por cinco itens, que refletem a atitude do indivíduo diante das experiências insatisfatórias. A segunda refere-se aos Benefícios Sociais do ato de reclamar, composta por três itens sobre a atitude da pessoa em relação a potenciais benefícios proporcionados a outros clientes pelo ato de reclamar.

Conforme Fishbein e Ajzen (1972), presume-se que a atitude perante a reclamação é correlacionada positivamente com a intenção de reclamação. Assim, consumidores insatisfeitos e com uma atitude favorável à reclamação tendem a reclamar diretamente à firma (Day \& Landon, 1977). Com base nesta lógica, é sugerido que:

H4: A atitude em face da reclamação influenciará positivamente a intenção de reclamação.

A alienação do consumidor é definida como um sentimento negativo do cliente perante as práticas empresariais (Singh, 1989). Quanto mais alienado for o cliente, maior será a sua tendência a ter uma atitude negativa ante as ações das empresas. A alienação também é capaz de influenciar a expectativa do cliente, pois os clientes alienados tendem a esperar desempenhos medíocres em situações de compra (Singh \& Wilkes, 1996). Além disso, os alienados sentem-se sem suporte das empresas e, portanto, percebem a probabilidade de sucesso da reclamação como menor. Assim, tem-se o seguinte grupo de hipóteses do trabalho:

H5: A alienação do consumidor influenciará negativamente a atitude em face da reclamação. 
H6: A alienação influenciará negativamente a probabilidade percebida de sucesso da reclamação.

Sobre a probabilidade percebida de retorno positivo, está bem documentada na literatura sua influência positiva nas intenções de reclamação (Richins, 1983; Singh, 1990). Se o consumidor acredita que a reclamação à empresa é um instrumento para atingir um nível ideal de satisfação, a avaliação cognitiva irá motivar o consumidor a reclamar e não a desenvolver outros comportamentos pós-insatisfação (Dabholkar, 1994). Portanto, tem-se que:

H7: A probabilidade percebida de sucesso da reclamação terá impacto positivo na intenção de reclamação.

Sobre as intenções de troca de fornecedor e comunicação boca-a-boca negativa, a probabilidade de sucesso parece impactar negativamente. Quando percebida como alta, a probabilidade de sucesso evidencia que o consumidor acredita na excelência da companhia. Portanto, ao lidar com uma empresa com boa reputação e que, conseqüentemente, sinaliza alta probabilidade de sucesso da reclamação, o consumidor demonstrará intenções de boca-a-boca negativa e troca de fornecedor menores. Com base nesta lógica, é proposto que:

H8: A probabilidade de sucesso percebida da reclamação terá impacto negativo na intenção de boca-a-boca negativa.

H9: A probabilidade de sucesso percebida da reclamação terá impacto negativo na intenção de troca de fornecedor.

O modelo de personalidade infere que há uma predisposição natural dos consumidores, a qual influencia seu comportamento pós-insatisfação (Landon, 1977; Richins, 1983). A autoconfiança do consumidor é definida como a "extensão com que um indivíduo se sente capaz e seguro sobre suas decisões e comportamentos em relação ao mercado de consumo" (Bearden, Hardesty, \& Rose, 2001,p. 121) e reflete um importante traço de personalidade que influenciaria positivamente o comportamento de reclamação. Os autores complementam que a autoconfiança "funciona para possibilitar o consumidor a operar efetivamente e a agir quando deparado com situações complexas, como decisões envolvendo um grande número de informação e tensões e pressões ocasionadas pelo mercado de consumo" (Bearden et al., 2001, p. 122), estabelecendo, assim, um vínculo entre a autoconfiança e a propensão do consumidor a agir e a buscar seus direitos. Portanto, espera-se uma forte relação entre autoconfiança e intenção de reclamação. Com base nisso, tem-se a seguinte hipótese:

H10: A autoconfiança do consumidor terá impacto positivo na intenção de reclamação. 
A ausência de pesquisas anteriores sobre as relações entre a autoconfiança e as intenções de comunicação boca-a-boca e de troca de fornecedor não nos permitiria elaborar hipóteses mais específicas a priori. Porém, assim como a autoconfiança indica propensão a agir no sentido de reclamar à empresa, acreditase que levaria também a ações ligadas à comunicação do problema e à intenção de abandonar o fornecedor em questão, conforme as hipóteses:

H11: A autoconfiança do consumidor terá impacto positivo na intenção do bocaa-boca negativa.

H12: A autoconfiança do consumidor terá impacto positivo na intenção de troca.

Conforme Singh e Pandya (1991), o poder da atitude perante a reclamação de explicação do consumidor depende do nível de insatisfação. Eles verificaram como positivo o efeito moderador do nível de insatisfação na relação entre atitude e reclamação real dos consumidores. Recentemente, Voorhees e Brady (2005) atestaram o oposto, ou seja, que o efeito do nível de insatisfação na intenção de reclamação depende da atitude do consumidor em face da reclamação. Baseandose na teoria de atitudes (Fishbein \& Ajzen, 1972), pode ser inferido que as atitudes do indivíduo moderam estímulos situacionais, tais como insatisfação percebida num encontro específico, e ações de resposta a ele. Dessa forma, é provável que consumidores com alta atitude diante da reclamação agirão conforme o estímulo a que forem expostos, ou seja, ao nível de insatisfação percebido. Alternativamente, intenções futuras de reclamação para um consumidor com baixa predisposição a reclamar serão menos guiadas pelo nível de insatisfação, pois tal consumidor provavelmente não reclamará, mesmo estando bastante insatisfeito. Portanto o efeito direto do nível de insatisfação na intenção de reclamação será relegado a um papel menor nesse caso. Tratando-se de intenções de reclamação, o presente estudo, da mesma forma que Voorhees e Brady (2005), sugere que a atitude modera a relação entre nível de insatisfação e intenção de reclamação.

H13: A atitude em face da reclamação modera a relação entre o nível de insatisfação e a intenção de reclamação do consumidor.

Baseando-se na fundamentação teórica e nas hipóteses estabelecidas, a Figura 1 apresenta o modelo estrutural teórico a ser investigado. A idéia central trazida pelo modelo é que o nível de insatisfação afetará as respostas do cliente ao problema. As variáveis individuais (alienação e probabilidade de sucesso) e de personalidade (atitude ante a reclamação e autoconfiança) também influenciarão as ações pós-insatisfação; a influência da atitude em face da reclamação ficará restrita à intenção de reclamação, e a alienação à forma indireta, via atitude diante à reclamação e a probabilidade de sucesso. 


\section{Figura 1: Modelo Estrutural para se Entender as Ações Pós-insatisfação}

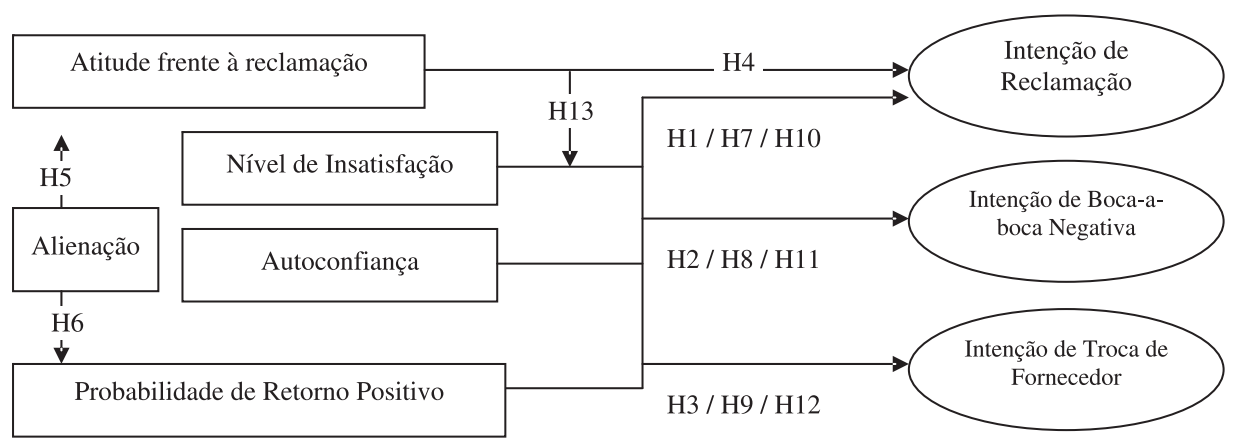

\section{Método}

A análise da intenção de reclamação e das demais ações pós-insatisfação requereu a utilização de um estudo experimental. Foi preciso um método capaz de medir a insatisfação, como variável independente, e as ações posteriores ao incidente, como variáveis dependentes. $O$ desenho quase-experimental apresentou os requisitos necessários para tal aplicação, porquanto, por meio dele, manipulações de insatisfação puderam ser realizadas dentro de situações controladas e, assim, o efeito da insatisfação sobre as ações em face dela pôde ser verificado.

\section{Procedimentos de Amostragem e Coleta de Dados}

A pesquisa desenvolveu-se em três etapas. A primeira consistiu em 16 entrevistas em profundidade; o objetivo foi explorar as percepções do problema de pesquisa, sedimentar as hipóteses de pesquisa, refinar as dimensões a serem incluídas na fase quantitativa, os atributos que melhor medirão essas dimensões e identificar os serviços que pudessem ser usados na etapa experimental. A partir dos dados obtidos nesta etapa e na revisão da literatura, foi delineado um experimento inicial e elaborado um instrumento de coleta de dados (questionário estruturado) a ser utilizado na etapa descritiva conclusiva.

A partir das entrevistas em profundidade e de estudos experimentais anteriores (p.ex., Wirtz \& Mattila, 2004), foi definido o design quase-experimental de um fator, em que foram impostos, em nível de insatisfação, dois tratamentos distintos (nível baixo e alto) manipulados através da severidade das falhas descritas (Anexo A). A segunda etapa consistiu no pré-teste, ou ensaio para o estudo principal, com 22 consumidores. De acordo com Aaker, Kumar e Day (2001), um pré-teste deve dar a oportunidade aos respondentes de expressarem suas frustrações com 
questões específicas e identificar problemas em relação ao escopo das questões. Nessa etapa, testou-se o delineamento do experimento e o instrumento de coleta de dados com o intuito de verificar a adequação de ambos aos objetivos da pesquisa. Após o estudo pré-experimental, foi aplicado o questionário no mês de outubro de 2005 a 480 estudantes de graduação de duas grandes universidades do Sul do Brasil. Cada entrevistado respondeu ao questionário com base em apenas um dos cenários. O objetivo foi o de provocar diferentes níveis (alto e baixo) de insatisfação conforme o cenário apresentado. Os entrevistados foram solicitados a imaginar que estavam experimentando a situação descrita, envolvendo falhas em uma experiência de jantar em restaurante. A eficácia das manipulações é aspecto crucial na pesquisa experimental, pois se deve buscar maximizar as diferenças nas variáveis independentes, para verificar seu efeito nas variáveis dependentes (Churchill, 1999). O teste de significância $(F=162.543 ; p<0,000)$ corroborou a forte diferença nas médias de insatisfação entre os dois grupos, validando a manipulação desejada.

Previamente à análise de dados, procedeu-se à sua preparação. Foram realizadas análises de casos omissos, extremos (outliers) e de normalidade e homoscedasticidade - também chamada de homogeneidade de variâncias - dos dados. A análise de casos omissos foi feita visualmente, pois o pesquisador, na digitação dos dados, verificou que quase não havia itens com não-resposta e que nenhum padrão foi identificado, permitindo inferir que as não-respostas foram aleatórias. Em seguida, foi feita a análise de outliers. Nenhum outlier univariado com três ou mais desvios-padrão de distância da média foi encontrado. A análise de outliers multivariados foi feita por meio do cálculo da distância de Mahalanobis. Foram excluídos 2 outliers multivariados. Os indicadores de curtose sinalizam uma distribuição não normal dos dados. Entretanto a análise de normalidade revelou que nenhuma variável estava fora dos padrões aceitos de normalidade. Os índices estavam dentro do recomendado por Kline (1998), curtose acima de 8 e skew acima de 3. A homoscedasticidade foi aferida pelo teste Box's M. A estatística F não significativa revela que não há diferenças nas matrizes de covariância entre os grupos, dando suporte à suposição de homogeneidade.

\section{Operacionalização das Variáveis}

As medidas do estudo (Anexo B) foram basicamente retiradas dos seguintes estudos: nível de insatisfação - 1 item (Richins, 1983); atitude frente à reclamação - 8 itens (Richins, 1983); alienação - 5 itens (Singh, 1989); probabilidade percebida de retorno positivo - 3 itens (Singh, 1990); autoconfiança - 12 itens (Bearden et $a l ., 2001$ ); e intenção de ações pós-insatisfação - 6 itens (Singh, 1990). O nível de insatisfação do cliente em face do cenário descrito foi coletado por meio de uma variável intervalar, conforme sugestão de Bagozzi (1977), de que a utilização de 
Modelagem de Equações Estruturais [MEE] em estudos experimentais faz-se mais bem aplicada, quando as variáveis são intervalares ou, pelo menos, manipuladas em três níveis. As medidas, originais de estudos norte-americanos, foram traduzidas para a língua portuguesa por meio da técnica de tradução reversa, submetidas à análise de conteúdo e medidas por meio de uma escala Likert de 5 pontos ( 1 =muito improvável e 5=muito provável, para ações pós-reclamação e probabilidade percebida de retorno positivo; $1=$ extremamente não-característico e 5=extremamente característico, para autoconfiança; 1=discordo totalmente e $5=$ concordo totalmente, para alienação e atitude em face da reclamação; e 1=mínima insatisfação e 5=máxima insatisfação, para nível de insatisfação).

\section{Processos Estatísticos de Análise}

Os métodos estatísticos para a investigação dos dados incluem: estatísticas descritivas e análise multivariada. Foram utilizados os softwares SPSS 13 e EQS 5.7. Entendendo-se que o objetivo central deste trabalho é testar as hipóteses e examinar a significância estatística do modelo proposto, foi utilizada a MEE. Foi investigado um modelo híbrido que permite estimar empiricamente os relacionamentos estabelecidos entre os construtos latentes, combinando o modelo de medidas, previamente testado, com o modelo estrutural estimado. A hipótese de moderação (relacionada à atitude em face da reclamação) foi testada por meio da Análise de Equações Estruturais Multigrupos. Esta abordagem permite que se estime simultaneamente o modelo teórico para cada grupo, nesses casos, os que possuem atitude mais alta e os de atitude mais baixa em face da reclamação. Assim, é possível testar se os coeficientes estimados variam para ambos (Singh, Verbeke, \& Rhoads, 1996).

\section{Resultados}

Os resultados deste trabalho serão apresentados da seguinte forma: primeiramente será feita uma caracterização geral da amostra. A seguir, o modelo de medidas será examinado, através da Análise Fatorial Confirmatória. Somente após o estabelecimento da validade e confiabilidade das medidas utilizadas é que o exame do modelo estrutural é realizado. Finalmente, a hipótese moderadora é investigada.

\section{Caracterização da Amostra}

A partir da coleta de dados nas salas de aula, um número amostral de 480 entrevistados foi alcançado, sendo 240 para cada cenário (baixa e alta insatisfação). 
Sessenta por cento dos respondentes são homens. A média de idade é de 24 anos (d.p. =6,93). Quarenta e seis por cento dos entrevistados (46\%) têm renda familiar mensal maior do que quatro mil reais; $31,5 \%$ de 2 a 4 mil reais; e $24 \%$ têm renda inferior a dois mil reais.

A maior parte dos entrevistados costuma comer em restaurantes mais de três vezes ao mês (56,5\%); 23,4\% costuma comer entre uma e três vezes; e 20\% menos que uma vez ao mês. Este resultado evidencia que a situação sugerida no cenário é conhecida, o que facilita que os respondentes se imaginem nela. Mais da metade $(57,3 \%)$ teve alguma experiência real insatisfatória com algum restaurante nos 12 meses anteriores à coleta. Dos que tiveram algum problema, 28,4\% apenas reclamou; $2 \%$ reclamou e não voltou mais ao estabelecimento; $10 \%$ reclamou e falou mal do restaurante; e 17\% não voltou, reclamou e falou mal. Os dados ainda mostram que 19,6\% apenas não voltou ao estabelecimento; $15 \%$ somente falou mal do restaurante; e $8 \%$ não voltou e falou mal. Esses dados evidenciam que boa parte dos entrevistados toma mais de uma ação em face de uma situação insatisfatória, indo ao encontro dos resultados de Day e Landon (1977) e Singh (1990): o comportamento pós-insatisfação é exibido em múltiplas maneiras.

Quanto à pesquisa realizada, a média do item não voltará a freqüentar esse local novamente $(4,07)$ indica a forte intenção dos clientes pouco ou muito insatisfeitos a trocar de fornecedor. Em relação ao item sobre a intenção de comunicação boca-a-boca negativa falará aos seus amigos e parentes sobre sua insatisfação com o restaurante, a média também se mostrou elevada $(3,75)$, reforçando a intenção dos clientes insatisfeitos a falar mal da empresa a parentes e conhecidos. Sobre a intenção de reclamação, a média do item definitivamente reclamará ao restaurante $(3,42)$ mostra que os clientes, embora não tão acentuadamente como falar mal e trocar de fornecedor, pretendem reclamar.

\section{Discussão sobre o Modelo de Medidas}

A partir das recomendações de vários autores, a validade do modelo é confirmada, se: (a) o modelo de medidas se ajustar aos dados razoavelmente bem, isto é, dentro dos índices de ajustamento considerados satisfatórios; (b) as cargas fatoriais dos indicadores nos fatores correspondentes forem grandes e significativas; (c) indicadores de um mesmo construto produzirem índices de confiabilidade superiores a 0,70 e variância extraída acima de 0,50; (e) análise de correlações entre construtos indicar validade discriminante (Santos \& Rossi, 2002).

$\mathrm{O}$ modelo da medida produziu os seguintes índices finais de ajustamento bastante satisfatórios $\left(\chi^{2} / \mathrm{GL}=2,01 ; \mathrm{CFI}=0,95 ; \mathrm{NFI}=0,91 ; \mathrm{RMSEA}=0,06\right)$. A validade convergente foi apoiada basicamente porque todos os itens 
apresentaram coeficientes fatoriais elevados e significativos nos respectivos construtos. Os parâmetros estimados revelam que as cargas fatoriais, sem exceção, são estatisticamente significativas e substancialmente grandes (de 0,59 a 0,87 , t-value 7,57). Além disso, as estimativas de confiabilidade variaram de 0,72 a 0,89 (intenção de troca de fornecedor e atitude em face da reclamação, respectivamente), e da variância extraída de 0,53 a 0,76 (experiência anterior de reclamação e intenção de reclamação, respectivamente). A validade discriminante entre os construtos foi verificada por meio de um procedimento proposto por Bagozzi e Phillips (1982), em que a validade discriminante entre dois construtos é avaliada restringindo-se a apenas um parâmetro que estabelece a relação entre os construtos. Compara-se esse modelo com outro, em que o parâmetro não é fixado e se faz um teste de diferença qui-quadrado. Se o teste indicar uma diferença qui-quadrado significante, quando a correlação não é restrita, isso indica haver validade discriminante entre os construtos. Esse procedimento foi realizado entre cada construto; todos os outros e todos os testes indicaram haver validade discriminante entre os construtos constituintes do modelo. Além disso, uma vez que os indicadores possuem carga fatorial elevada com seus respectivos construtos latentes e baixos valores de resíduos ajustados é um sinal claro de validade discriminante.

\section{Discussão do Modelo Estrutural}

Após a análise das medidas, o foco do estudo volta-se à estrutura teórica desenvolvida. A investigação das hipóteses foi perseguida, basicamente, pelos níveis do ajuste do modelo híbrido, e pela significância e pelo valor dos coeficientes estimados da regressão (Hair, Anderson, Tatham, \& Black, 1998; Kline, 1998). Além disso, o coeficiente de determinação foi estabelecido para cada equação estrutural, similar ao encontrado na regressão múltipla.

Os resultados da análise do modelo estrutural, tendo como base o banco de dados com 480 clientes, encontram-se na Tabela 1. O valor do qui-quadrado é significativo. Porém, sabendo-se que este teste é muito sensível a desvios da normalidade e a amostras superiores a 200, a análise do valor do qui-quadrado deve ser feita em composição com os outros critérios de ajustamento (Hair et al., 1998). Verificando-o sobre os graus de liberdade, produz um valor satisfatório 2,01, bem menor que o máximo recomendado (5). Os índices de ajustamento CFI, NFI, NNFI, todos bem acima de 0,90 , são considerados bastante satisfatórios e o RMSEA de 0.06 está entre valores recomendados de 0.05 e de 0.08 ; assim, é aceitável. 


\section{Tabela 1: Coeficientes de Regressão Estimados às Relações Teóricas Propostas no Modelo}

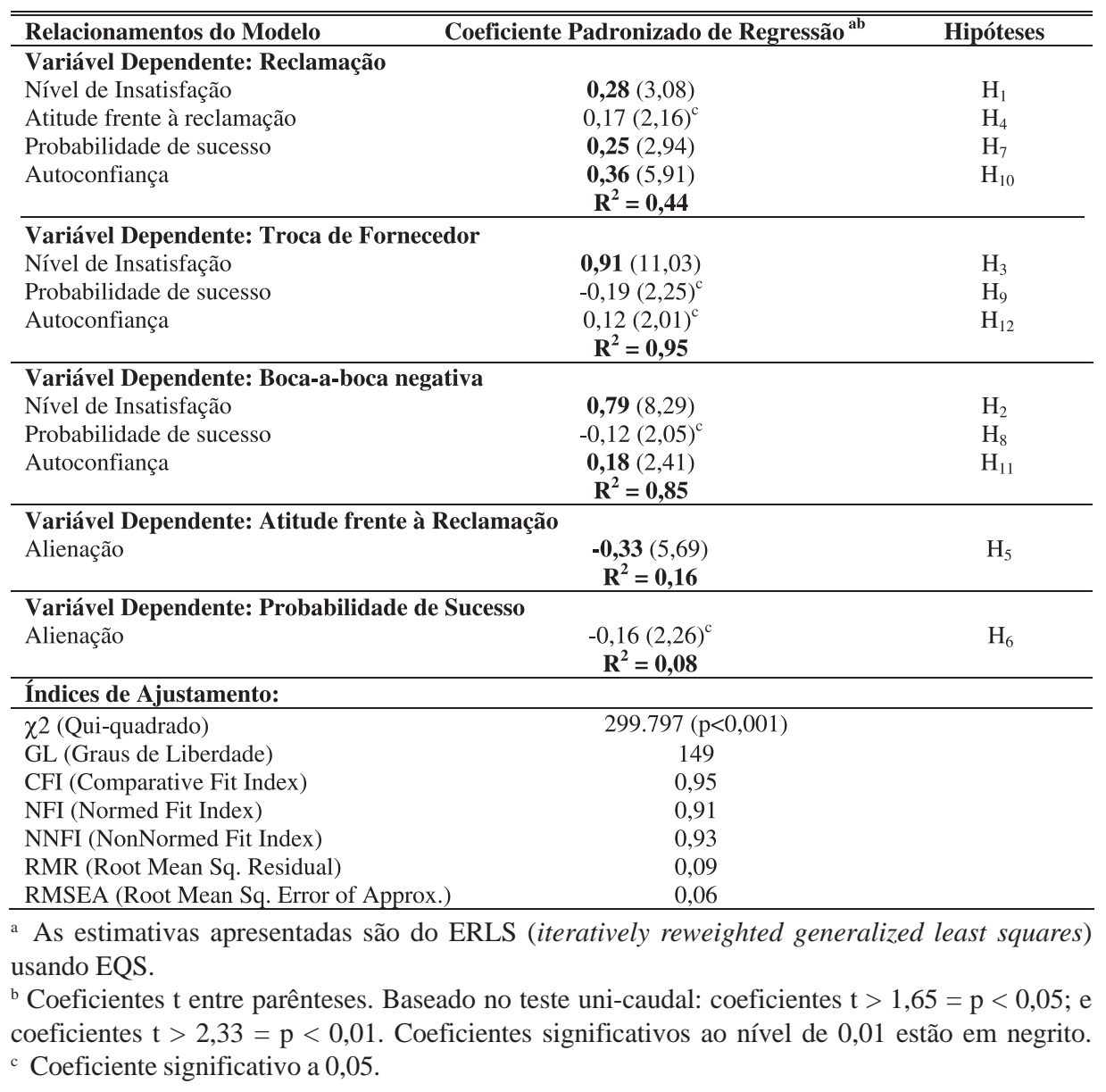

Os resultados fornecem a sustentação para todos os relacionamentos nomológicos especificados pelo modelo, isto é, das relações que refletem o impacto: 1) da autoconfiança; 2) do nível da insatisfação; e 3) da probabilidade percebida do sucesso nas intenções de reclamação, comunicação boca-a-boca negativa e troca de fornecedor; 4) da atitude em face da reclamação na intenção de reclamação; 5) da alienação na atitude perante a reclamação e na probabilidade percebida de retorno positivo à reclamação.

De acordo com as hipóteses $\mathrm{H}_{1}, \mathrm{H}_{4}, \mathrm{H}_{7}$ e $\mathrm{H}_{10}$, sobre o impacto dos antecedentes na intenção de reclamação, podemos verificar que apenas a atitude em face da reclamação não teve efeito altamente significativo. A magnitude dos coeficientes de regressão foi analisada por meio do teste $t$, na medida em que o coeficiente $t$ 
verifica a significância das relações entre as variáveis a partir de 0 , isto é, sem efeito (Hair et al., 1998). Pode ser observado na Tabela 1 que a atitude perante a reclamação teve o menor efeito entre os antecedentes da intenção de reclamação, obtendo coeficiente t de 2,16 , isto é, significativo apenas no nível 0,05 de significância (coeficiente $\mathrm{t}>1,65=\mathrm{p}<0,05$; e coeficiente $\mathrm{t}>2,33=\mathrm{p}<0,01)$.

Uma vez que os coeficientes padronizados de regressão podem ser interpretados como coeficientes beta padronizados em um modelo de regressão múltipla, os resultados indicam que o impacto do nível de insatisfação $(0,28)$ na intenção de reclamação é maior que o impacto da probabilidade de sucesso $(0,25)$ e o da atitude em face da reclamação $(0,17)$, porém menor que o impacto da autoconfiança $(0,36)$. O R $\mathrm{R}^{2}$ de 0,44 reflete um razoável poder explicativo destas variáveis com relação à intenção de reclamação. Sobre a intenção de troca de fornecedor, com relação às hipóteses $\mathrm{H}_{3}, \mathrm{H}_{9}$ e $\mathrm{H}_{12}$, pode-se verificar que o nível de insatisfação exerceu influência principal sobre esta variável $(0,91)$, e que a probabilidade de sucesso $(-0,19)$ e a autoconfiança $(0,12)$ exerceram papel pouco significativo.

Os resultados também confirmam as hipóteses $\mathrm{H}_{2}, \mathrm{H}_{8}$ e $\mathrm{H}_{11}$, em que são estabelecidas as relações entre nível de insatisfação, probabilidade de sucesso e autoconfiança na comunicação do boca-a-boca negativo. Os resultados novamente mostram o papel central do nível de insatisfação na determinação deste tipo de comportamento $(0,79)$. O R $\mathrm{R}^{2}$ de 0,85 indica que o nível de insatisfação, a probabilidade de sucesso e a autoconfiança foram capazes de prever boa parte das variações do boca-a-boca negativo. Finalmente, os resultados também confirmam a hipótese $\mathrm{H}_{5}$, sobre o impacto da alienação na atitude em face da reclamação. Apesar de significativo (-0,33; coeficiente $\mathrm{t}=5,69)$, o poder explicatório dessa variável nas atitudes diante da reclamação é considerado baixo $\left(R^{2}-0,16\right)$. $\mathrm{A} \mathrm{H}_{6}$ sobre o efeito da alienação na probabilidade de sucesso foi parcialmente confirmada, pois o poder explicatório da alienação foi ainda menor neste caso $\left(\mathrm{R}^{2}-0,08\right)$.

Como já foi dito, os impactos do nível de insatisfação nas intenções de troca de fornecedor $(0,91)$ e do boca-a-boca negativo $(0,79)$ apresentaram-se altamente significativos, indo ao encontro de pesquisas anteriores, em que o nível de insatisfação influenciou fortemente os aspectos relacionados à lealdade (Buttle \& Burton, 2002; Singh, 1990). Assim, parece que o efeito da insatisfação na troca de fornecedor e na comunicação boca-a-boca é dominante, ao passo que seu efeito na intenção de reclamação é um pouco menor, dando lugar à autoconfiança, como antecedente principal entre os testados.

A análise de moderação presente neste trabalho destaca possíveis diferenças na intensidade das relações nomológicas estabelecidas entre nível de insatisfação 
e intenção de reclamação por conta do nível da atitude em face da reclamação dos clientes. Com atitude baixa, a influência da insatisfação na intenção de recompra seria mais fraca do que quando a atitude fosse alta. Para que ela seja testada, foi necessário, portanto, que se segmente o banco de dados com 480 respondentes, entre o grupo de clientes que percebem a atitude perante a reclamação como sendo alta (186 respondentes) e o grupo dos que percebem como baixa (163). Para isso os valores desta variável (média dos itens que a mediram) foram divididos em 3 partes iguais e usou-se o 1/3 mais alto e 1/3 mais baixo, respectivamente, para mais precisamente refletir a natureza da moderação, que poderia ser ofuscada, se valores intermediários da variável fossem incluídos. Os primeiros indicaram níveis de atitude entre 4,12 e 5 (ponto máximo na escala) e os segundos apresentaram níveis entre 0 e 3,62.

Para testar o efeito de moderação da atitude ante a reclamação no modelo proposto, estimou-se o modelo simultaneamente para cada grupo de consumidores, através da MEE Multigrupos. Seguindo os procedimentos indicados por Kline (1998), inicialmente, restringiram-se todos os parâmetros como invariantes nos dois grupos e se estimou um modelo totalmente restrito. Subseqüentemente, com base no teste Lagrange-multiplier, liberaram-se os parâmetros com indicadores significativos; e a cada liberação foi verificado o valor do qui-quadrado, para testar a significância da moderação até o momento em que esta liberação não melhorasse significativamente o modelo. Os coeficientes estimados finais são apresentados na Tabela 2. Os índices de ajustamento ao modelo $(\chi 2=228.455$, $\mathrm{gl}=168, \chi 2 / \mathrm{gl}=1,47, \mathrm{NFI}=0,90, \mathrm{NNFI}=0,92, \mathrm{CFI}=0,94 \mathrm{e} \mathrm{RMSEA}=0,06)$ foram satisfatórios.

\section{Tabela 2: Coeficientes Estimados à Relação para Clientes com Diferentes Níveis de Atitude ${ }^{\mathrm{a}}$}

\begin{tabular}{lcc}
\hline \hline Variável Dependente: Intenção de Reclamação & Atitude Alta & Atitude Baixa \\
\hline $\mathrm{R}^{2}$ & 0,62 & 0,31 \\
Nível de Insatisfação & $0,41(6,07)$ & $0,15(2,13)$ \\
\hline
\end{tabular}

a as estimativas apresentadas são do ERLS (iteratively reweighted gereneralized least squares) usando EQS.

Os parâmetros estruturais estimados, apresentados na Tabela 2, indicam que a relação entre nível de insatisfação e a intenção de reclamação difere entre os grupos de consumidores com diferentes atitudes em face da reclamação. Enquanto, entre os consumidores com atitude mais alta, a insatisfação produz impacto de 0,41 , entre os de atitude mais baixa, o impacto cai para 0,15 . O coeficiente de determinação, entre aqueles com atitude mais alta é de $62 \%$. Esta porcentagem cai para aproximadamente $31 \%$ entre os clientes com atitude mais baixa. 
Este resultado reforça a idéia de que um cliente com atitude alta, quando se depara com algum problema, parece tomar a ação de acordo com suas avaliações sobre o problema; sendo o incidente grave, esse cliente provavelmente reclamará. Já os clientes com atitude baixa, mesmo avaliando o problema como grave, não tomam ação de reclamação. Isto significa que a atitude elevada em face da reclamação é condição fundamental para a tradução da insatisfação em registro de reclamação. É importante, portanto, desenvolver atitudes positivas em face do ato de reclamar, para que as reclamações sejam realizadas com maior facilidade.

\section{Implicações e Limitações da Pesquisa}

Com algumas poucas exceções, como os trabalhos de Day e Landon (1977), Folkes (1984) e Singh (1988), as pesquisas do comportamento pós-insatisfação têm falhado no reconhecimento da multidimensionalidade das respostas reclamatórias. Richins (1983), por exemplo, investigou a comunicação boca-aboca e Gilly e Gelb (1982) enfatizaram as questões de recompra. Deste modo, estudos como o presente, que investigam toda a variedade de respostas utilizadas pelos clientes são, mais do que interessantes, necessários.

Este estudo investigou algumas questões relevantes e ainda inexploradas no campo de conhecimento considerado, entre elas: (1) a consideração das respostas à insatisfação envolvendo uma série de intenções de ação; (2) o papel do nível de insatisfação nas respostas pós-insatisfação; (3) o impacto de variáveis individuais e de personalidade sobre as ações pós-insatisfação; (4) a aplicabilidade de medidas norte-americanas no contexto brasileiro.

Os resultados univariados indicam a intenção de ação do consumidor em face de uma experiência insatisfatória de consumo. Os resultados demonstram que a maior parte $(72,7 \%$ - somando-se as concentrações de freqüência nas opções quatro e cinco) não voltará ao local, boa parte $(63,2 \%)$ falará a amigos e parentes sobre a insatisfação que experimentou, e pouco mais da metade $(52,1 \%)$ indicou que provavelmente reclamará ao restaurante.

O nível de insatisfação mostrou influência bastante significativa nas intenções do boca-a-boca negativo e de troca de fornecedor. Neste sentido, os consumidores que pretendem comentar com outras pessoas o problema ou trocar de empresa fornecedora possuem nível de insatisfação significativamente mais alto do que aqueles que não pretendem.

A idéia de que as ações reclamatórias são influenciadas pelo grau de insatisfação também foi referendada nesta pesquisa. Entretanto, sobre essas ações, a 
autoconfiança exerce influência maior do que o nível de insatisfação. As demais variáveis (probabilidade de sucesso e atitude em face da reclamação) também exercem impacto significativo. Isso parece ter implicações importantes para os profissionais de marketing, pois indica que, excetuando-se a autoconfiança (que é praticamente desenvolvida através de outras atividades e vivências do consumidor), as ações da empresa em situações anteriores com o cliente e com seu grupo de referência podem gerar uma percepção de maior probabilidade de sucesso e também atitudes mais elevadas em face do ato de reclamar. As empresas, por exemplo, ao apresentarem uma postura proativa de atendimento às reclamações, estarão aumentando a probabilidade de sucesso percebida pelo cliente e melhorando, dessa forma, sua atitude em face de exigir seus direitos. Assim, as empresas podem aumentar o número de reclamação e minimizar os casos em que o cliente, após uma experiência insatisfatória de consumo, apenas troca de fornecedor e/ou fala para amigos e parentes da experiência ruim que teve com tal empresa.

É importante ressaltar que os coeficientes de determinação alcançados foram todos expressivos e indicam que as variáveis independentes foram capazes de predizer boa parte das mudanças nas variáveis dependentes, conforme o referencial teórico previa. Ainda quanto ao comportamento de reclamação, o efeito moderador da atitude em face da reclamação mostra que a insatisfação dos clientes será mais facilmente traduzida em reclamação naqueles clientes com atitudes mais elevadas em face da reclamação. Já entre os que apresentam atitude mais baixa, o nível de insatisfação pouco influencia a intenção de reclamação.

Este trabalho procura trazer não só uma contribuição teórica para aqueles que lidam com o comportamento do consumidor, mas também uma contribuição prática para aqueles que, dentro das empresas, procuram estabelecer uma filosofia realmente voltada ao consumidor, entendendo que o trabalho do profissional de marketing não termina, quando o produto é comprado, mas continua durante o período pós-compra, em que se torna importante o monitoramento de todo o elenco de caminhos que estará à disposição do consumidor, caso seja experimentado algum sentimento de insatisfação com o produto ou serviço. Os fatores do comportamento de pós-insatisfação dos clientes são relevantes às empresas, pois podem ser utilizados estrategicamente para aumentar o número de clientes reclamantes e obter, assim, os benefícios desse comportamento. Além disso, o alto impacto da autoconfiança na intenção de reclamação revela que a empresa, ao gerenciar as reclamações, está lidando com clientes mais autoconfiantes e que percebem suas ações, como consumidores, como mais bem sucedidas. 
Essa informação revela a necessidade da empresa em projetar estratégias de recuperação de serviços que satisfaçam clientes mais autoconfiantes e que têm, portanto, maior certeza das suas convicções. Um cliente não volta à empresa para reclamar simplesmente porque está insatisfeito; ele reclama porque acredita em sua capacidade de obter uma resposta satisfatória da empresa e, também, porque percebe que a empresa é capaz de lhe fornecer tal retorno positivo. Ademais, isso indica que a empresa deve ser proativa na busca de uma avaliação do serviço prestado. Por exemplo, não basta deixar na mesa do restaurante, à disposição do cliente, um formulário de avaliação do serviço. O garçom ou o gerente deve explicar que a avaliação é importante e diretamente pedir que o formulário seja preenchido ou a queixa expressada. Isso servirá para aumentar o número de clientes reclamantes, bem como a probabilidade daqueles clientes menos autoconfiantes e com baixa atitude em face da reclamação de expressarem sua insatisfação, permitindo à empresa reverter a situação.

Os resultados também indicam, pelo impacto do nível de insatisfação bastante significativo nas intenções de comunicação boca-a-boca negativa e troca de fornecedor, que as falhas de serviço, sem um processo de recuperação, podem diminuir as vendas da empresa.

As contribuições trazidas por este estudo devem ser ponderadas pelas limitações que o cercaram. A primeira limitação refere-se à amostra utilizada, não probabilística e composta por estudantes. Sob esta perspectiva, a generalização dos resultados é fortemente limitada. Notadamente, a aplicação de experimentos, com a manipulação das variáveis estudadas, permitiu o teste das associações causais entre o nível de insatisfação e as intenções de ações pós-insatisfação neste trabalho. Isto foi possível pelo fato de que, em geral, os experimentos produzem maior validade interna ao eliminar os efeitos de variáveis externas que poderiam confundir ou obscurecer os relacionamentos estudados, permitindo concluir que o fenômeno observado é realmente devido à manipulação das variáveis (Churchill, 1999). Entretanto a utilização dessa técnica inviabilizou a inclusão da influência das emoções (como a raiva, tristeza e angústia) nas ações pósinsatisfação. O uso de cenários torna difícil o estímulo de emoções e a representação fidedigna de quando geradas em ambientes reais de falhas em encontros de serviço. Outra limitação refere-se à especificidade do cenário utilizado, envolvendo falhas num restaurante. A fim de se testar a estabilidade do modelo construído, sugere-se a aplicação da pesquisa em outros setores.

Quanto às variáveis individuais e de personalidade, poucos estudos têm abordado a formação dessas variáveis. Esforços devem ser feitos no que diz respeito à investigação delas, já que provaram ser relevantes na intenção de reclamação. Além disso, deve-se abordar outros antecedentes, gerais ou específicos de cada 
uma das intenções de ações pós-insatisfação, como, por exemplo, a influência dos custos de mudança na intenção de troca de fornecedor e da atribuição de culpa em todas as intenções.

\section{Artigo recebido em 07.08.2006. Aprovado em 02.08.2007.}

\section{NotAs}

${ }^{1} \mathrm{O}$ consumismo foi um movimento iniciado nos Estados Unidos no final da década de 60 com o objetivo de aumentar a qualidade de informação, educação e proteção do consumidor, buscando sua segurança na compra e na utilização de um produto ou serviço.

${ }^{2}$ Singh (1989), assim como outros autores, utilizam a expressão em inglês complaint behavior, referindo-se a todos os comportamentos pós-insatisfação e não apenas à reclamação em si. Por este motivo, preferiu-se aqui traduzir por comportamento pós-insatisfação para evitar confusões semânticas.

\section{ReferênCIAS Bibliográficas}

Aaker, D.,

Kumar, V., \&

Day, G. (2001).

Pesquisa de marketing. São Paulo: Atlas.

Andreasen, A. (1984).

Consumer satisfaction in loose monopolies: the case of medical care. Journal of Public Policy and Marketing, 2, 122-135.

Babin, B. J., \&

\section{Griffin, M. (1998).}

The nature of satisfaction: an updated examination and analysis. Journal of Business Research, 41(2), 127-136.

Bagozzi, R. P. (1977).

Structural equation models in experimental research. Journal of Marketing Research, 14(2), 209-226.
Bagozzi, R., \&

Phillips, L. (1982).

Representing and testing organizational theories: a holistic construal. Administrative Science Quarterly, 27(3), 459-489.

Bearden, W. O. (1983).

Profiling consumers who register complaints against auto repair services. Journal of Consumer Affairs, 17(2), 315-36.

Bearden, W., \&

Oliver, R. (1985).

The role of public and private complaining in satisfaction with problems resolution. Journal of Consumer Affairs, 19(2), 222-239. 
Bearden, W.,

Hardesty, D., \&

Rose, R. (2001).

Consumer self-confidence: refinement in conceptualization and measurement. Journal of Consumer Research, 28(1), 121-134.

Bitner, M. J.,

Booms, B. H., \&

Tetreault, M. (1990).

The service encounter: diagnosing favorable and unfavorable incidents. Journal of Marketing, 54, 71-84.

Blodgett, J., \&

Anderson, R. (2000).

A bayesian network model of the consumer complaint process. Journal of Service Research, 2(4), 321-338.

Buttle, F., \&

Burton, J. (2002).

Does service failure influence customer loyalty? Journal of Consumer Behaviour, 1(3), 217-228.

Chauvel, M. (2000, setembro).

Insatisfação e queixa à empresa: investigando os relatos dos consumidores. Anais do Encontro Nacional da Associação Nacional de Pós-Graduação e Pesquisa em Administração, Florianópolis, SC, Brasil, 24.

Churchill, G. (1999).

Marketing research. Orlando: Fryden Press.

Dabholkar, P. A. (1994).

Incorporating choice into an attitudinal framework: Analyzing models of mental comparison processes. Journal of Consumer Research, 21(1), 100-119.
Day, R. (1984).

Modeling choices among alternative responses to dissatisfaction with durable products. In R. Belk (Ed.). Advances in consumer research (11st ed.). Ann Arbor: ACR.

Day, R., \&

Landon, E. (1977).

Toward a theory of consumer complaining behavior. In A. Woodside \& J. Sheth (Eds.). Consumer and industrial buying behavior. New York: North Holland.

Evrard, Y.(1993).

La Satisfaction dês consummateurs: état des recherché. Revue Française du Marketing, 144-145(4-5), 53-65.

Fishbein, M., \&

Ajzen, I. (1972).

Attitudes and opinions. Annual Review of Psychology, 23, 487-545.

Folkes, V. (1984).

Consumer reactions to product failure: an attributional approach. Journal of Consumer Research, 10(4), 398-409.

Fornell, C., \&

Wernerfelt, B. (1987).

Defensive marketing strategy by customer complaint management. Journal of Marketing Research, 24(4), 337-346.

Giglio, E., \&

Chauvel, M. (2002, setembro).

Reclamação e cultura brasileira: um estudo baseado na análise de cartas de consumidores à imprensa. Anais do Encontro Nacional da Associação Nacional de Pós-Graduação e Pesquisa em Administração, Salvador, BA, Brasil, 26. 
Gilly, M. C., \&

Gelb, B. (1982).

Post-purchase consumer processes and the complaining consumer. Journal of Consumer Research, 9(3), 323-328.

Goodwin, C., \&

Ross, I. (1990).

Consumer evaluations of responses to complaints: what's fair and why. Journal of Consumer Marketing, 7(2), 39-48.

Gronhaug, K., \&

Zaltman, G. (1981).

Complainers and non-complainers revisited: another look at the data. Advances in Consumer Research, 8(1), 8, 83-87.

Hair, J.,

Anderson, R. E.,

Tatham, R., \&

Black, W. (1998).

Multivariate Data Analysis. New Jersey: Prentice Hall.

Herr, P.,

Kardes, F., \&

Kim, J. (1991).

Effects of word-of-mouth and information persuasion: accessibilitydiagnosticity perspective. Journal of Consumer Research, 17(4), 454-462.

Hirschman, A. (1970).

Exit, voice and loyalty. Cambridge: Harvard University Press.

Kim, C.,

Kim, S.,

Im, S., \&

Shin, C. (2003).

The effect of attitude and perception on consumer complaint intentions. The Journal of Consumer Marketing, 20(4), 352-371.

Kline, R. (1998).

Principles and practice of SEM. New York: The Guilford Press.

Landon, E. (1977).

A model of consumer complaint behavior. In R. Day (Ed.). Consumer satisfaction, dissatisfaction and complaining behavior. Bloomington: Indiana Univ. Press.

Maddox, R. N. (1981).

Two-factor theory and consumer satisfaction: replication and extension. Journal of Consumer Research, 8(1), 97-103.

Maute, M., \&

Forrester, W. (1993).

The structure and determinants of consumer complaint intentions and behavior. Journal of Economic Psychology, 14(2), 219-248.

Mittal, B., \&

Lassar, W. M. (1998).

Why do customers switch? The dynamics of satisfaction. Journal of Services Marketing, 12(2-3), 177-195.

Nyer, P. U. (2000).

An investigation into whether complaining can cause increased consumer satisfaction. Journal of Consumer Marketing, 17(1), 9-20.

Oliver, R. (1999).

Whence consumer loyalty? Journal of Marketing, 63(Special Issue), 3344. 
Reichheld, F. (1996).

Learning from defections. Harvard

Business Review, 74(2), 56-68.

50 anos de supermercado no Brasil. (2002). São Paulo: Fundação Abras.

Richins, M. L. (1983).

Negative word-of-mouth by dissatisfied consumers: a pilot study. Journal of Marketing, 47, 68-78.

Santos, C., \&

Rossi, C. (2002, setembro).

Os antecedentes da confiança do consumidor em episódios envolvendo reclamações sobre serviços. Anais do Encontro Nacional da Associação Nacional de Pós-Graduação e Pesquisa em Administração, Salvador, BA, Brasil, 26.

Singh, J. (1988).

Consumer complaint intentions and behavior: definitional and taxonomical issues. Journal of Marketing, 52(1), 93-108.

Singh, J. (1989).

Determinants of consumers' decisions to seek third party redress: an empirical study of dissatisfied patients. Journal of Consumer Affairs, 23(2), 329-354.

Singh, J. (1990).

Voice, exit and negative word-ofmouth behaviors: investigation across three service categories. Journal of the Academy of Marketing Science, 18(1), 1-16.

Singh, J., \&

Pandya, S. (1991).

Exploring the effects of consumers' dissatisfaction level on complaint behaviors. European Journal of Marketing, 25(9), 7-21.

Singh, J., \&

Wilkes, R. E. (1996).

When consumers complain: a path analysis of the key antecedents of consumer complaint response estimates. Journal of the Academy of Marketing Science, 24(4), 350-365.

Singh, J.,

Verbeke, W., \&

Rhoads, G. (1996).

Do organizational practices matter in role stress processes? A study of direct moderating. Journal of Marketing, 60, 69-86.

Technical Assistance Research Program. (1986).

Consumer complaint handling in America: an update study. Washington: White House Office of Consumer Affairs.

Tax, S.,

Brown, S., \&

Chandrashekaran, M. (1998).

Customer evaluations of service complaint experiences: implications for relationship. Journal of Marketing, 62(2), 60-76.

Voorhees, C. M., \&

Brady, M. K. (2005).

A service perspective on the drivers of complaint intentions. Journal of Service Research, 8(2), 192-204.

Wirtz, J., \&

Mattila, A. (2004).

Consumer responses to compensation, speed of recovery and apology after failure. International Journal of Service Industry Management, 15(2), 150-166. 


\section{ANEXO A:}

\section{Descrição dos Cenários do Estudo}

Imagine que você está vivendo a situação abaixo.

Cenário de Alta Severidade do Problema. Você e outra pessoa vão a um restaurante jantar para celebrar uma ocasião especial. Você havia feito uma reserva numa mesa com ótima localização; porém, ao chegar ao restaurante, foi informado de que o restaurante estava lotado e a mesa já estava ocupada. Após cinco minutos, vocês são transferidos para outra mesa. Vocês estão sentados. O garçom vem para pegar o seu pedido. Vocês fazem o pedido e o garçom informa que o prato solicitado não está disponível. Vocês escolhem outra opção e o garçom rispidamente informa que o restaurante também está sem esta segunda solicitação. Vocês finalmente escolhem uma terceira e disponível alternativa. Após uma hora, o garçom traz o prato solicitado.

Cenário de Baixa Severidade do Problema. Você e outra pessoa vão a um restaurante jantar para celebrar uma ocasião especial. Vocês estão sentados. O garçom vem para pegar o seu pedido. Vocês fazem o pedido e o garçom informa que o prato solicitado não está disponível. Vocês escolhem uma outra opção e, após quarenta minutos, o garçom traz o prato solicitado. 


\section{ANEXO B:}

\section{Medidas Operacionais Utilizadas para Analisar os Construtos}

\begin{tabular}{|c|c|c|c|c|}
\hline & $\begin{array}{l}\text { Alpha de } \\
\text { Cronbach }\end{array}$ & $\begin{array}{c}\text { Carga } \\
\text { Fatorial }\end{array}$ & $\begin{array}{l}\text { Confiab. } \\
\text { Compos. }\end{array}$ & $\begin{array}{l}\text { Varianc. } \\
\text { Extraída }\end{array}$ \\
\hline \multicolumn{5}{|l|}{ Intensidade da Insatisfação } \\
\hline \multicolumn{5}{|l|}{ 1. Qual o nível de insatisfação perante essa situação? } \\
\hline Intenção de Reclamação Direta à Empresa & 0,91 & & 0,88 & 0,76 \\
\hline \multicolumn{5}{|l|}{ Com que probabilidade você...: } \\
\hline 1. definitivamente reclamará ao restaurante? & & 0,78 & & \\
\hline $\begin{array}{l}\text { 2. chamará o garçom ou outro funcionário imediatamente e exigirá uma } \\
\text { solução para o problema? }\end{array}$ & & 0,89 & & \\
\hline Intenção de Comunicação Boca-a-boca Negativa & 0,94 & & 0,81 & 0,75 \\
\hline 3. falará aos seus amigos e parentes sobre sua insatisfação com o restaurante? & & 0,91 & & \\
\hline $\begin{array}{l}\text { 4. recomendará seus amigos e parentes a não freqüentar o restaurante em } \\
\text { questão? }\end{array}$ & & 0,95 & & \\
\hline Intenção de Troca de Fornecedor & 0,74 & & 0,72 & 0,54 \\
\hline 5. esquecerá o problema e não fará nada. ${ }^{1}$ & & 0,88 & & \\
\hline 6. não voltará a freqüentar esse local novamente. & & 0,94 & & \\
\hline Atitude em face da Reclamação - Normas Pessoais & 0,88 & & 0,89 & 0,72 \\
\hline \multicolumn{5}{|l|}{ Indique o seu grau de concordância com as seguintes afirmações: } \\
\hline $\begin{array}{l}\text { 1. É normal que as pessoas se deparem com produtos insatisfatórios de vez em } \\
\text { quando; então elas não devem reclamar. }\end{array}$ & & 0,69 & & \\
\hline $\begin{array}{l}\text { 2. Incomoda-me se não reclamo sobre uma compra insatisfatória (quando sei } \\
\text { que deveria). }\end{array}$ & & 0,89 & & \\
\hline $\begin{array}{l}\text { 3. Em geral, eu me sinto bem ao desabafar sobre minha insatisfação e } \\
\text { frustração com um produto por meio da reclamação. }\end{array}$ & & 0,75 & & \\
\hline $\begin{array}{l}\text { 4. Eu geralmente reclamo quando estou insatisfeito com algum produto ou } \\
\text { empresa, pois eu sinto que é meu dever fazer isso. }\end{array}$ & & 0,78 & & \\
\hline $\begin{array}{l}\text { 5. Eu não gosto de pessoas que reclamam a empresas, porque freqüentemente } \\
\text { suas reclamações são sem fundamento. }{ }^{1}\end{array}$ & & 0,72 & & \\
\hline \multicolumn{5}{|l|}{ Atitude em face da Reclamação - Benefícios Sociais } \\
\hline $\begin{array}{l}\text { 6. Ao reclamar sobre produtos insatisfatórios, no longo-prazo, a qualidade dos } \\
\text { produtos irá melhorar. }\end{array}$ & & 0,91 & & \\
\hline $\begin{array}{l}\text { 7. Ao reclamar sobre produtos com defeitos, eu posso estar prevenindo outros } \\
\text { consumidores de experimentarem o mesmo problema. }\end{array}$ & & 0,85 & & \\
\hline $\begin{array}{l}\text { 8. As pessoas têm a responsabilidade de contar às empresas quando um } \\
\text { produto comprado apresenta defeito. }\end{array}$ & & 0,59 & & \\
\hline Alienação do Consumidor & 0,85 & & 0,85 & 0,61 \\
\hline $\begin{array}{l}\text { 1. A maioria das empresas não se preocupa, de forma alguma, com o } \\
\text { consumidor. }\end{array}$ & & 0,75 & & \\
\hline 2. Em geral, as empresas são desonestas ao lidar com o consumidor. & & 0,70 & & \\
\hline 3. As empresas dão suporte aos produtos e garantias oferecidas. ${ }^{1}$ & & 0,61 & & \\
\hline $\begin{array}{l}\text { 4. O consumidor é geralmente o que menos importa para a maioria das } \\
\text { empresas. }\end{array}$ & & 0,80 & & \\
\hline $\begin{array}{l}\text { 5. Tão logo eles realizam a venda, a maioria das empresas se esquece do } \\
\text { cliente. }\end{array}$ & & 0,59 & & \\
\hline Probabilidade Percebida de Sucesso da Reclamação & 0,74 & & 0,81 & 0,55 \\
\hline $\begin{array}{l}\text { Assumindo que você reclame ao restaurante, com que probabilidade o } \\
\text { restaurante...: }\end{array}$ & & & & \\
\hline
\end{tabular}




\section{(conclusão)}

\section{Medidas Operacionais Utilizadas para Analisar os Construtos}

\begin{tabular}{|c|c|c|c|c|}
\hline & $\begin{array}{l}\text { Alpha de } \\
\text { Cronbach }\end{array}$ & $\begin{array}{c}\text { Carga } \\
\text { Fatorial }\end{array}$ & $\begin{array}{l}\text { Confiab. } \\
\text { Compos. }\end{array}$ & $\begin{array}{l}\text { Varianc. } \\
\text { Extraída }\end{array}$ \\
\hline $\begin{array}{l}\text { 1.Tomará a ação apropriada para resolver o problema (retorno do dinheiro } \\
\text { etc.). }\end{array}$ & & 0,67 & & \\
\hline $\begin{array}{l}\text { 2. Tomará a ação apropriada para resolver o problema e lhe oferecerá um } \\
\text { serviço melhor no futuro, caso você freqüente novamente o restaurante. }\end{array}$ & & 0,76 & & \\
\hline $\begin{array}{l}\text { 3. Vai oferecer-lhe um serviço melhor no futuro e isso beneficiará também } \\
\text { outros clientes. }\end{array}$ & & 0,73 & & \\
\hline Experiência Anterior de Reclamação & 0,67 & & 0,79 & 0,53 \\
\hline $\begin{array}{l}\text { 1. Durante os últimos } 12 \text { meses quantas vezes você reclamou de produtos ou } \\
\text { serviços insatisfatórios? }\end{array}$ & & 0,83 & & \\
\hline $\begin{array}{l}\text { 2. Se você reclamou à empresa, qual o seu nível de satisfação com os esforços } \\
\text { das empresas em resolver os problemas? }\end{array}$ & & 0,89 & & \\
\hline Autoconfiança & 0,83 & & 0,88 & 0,67 \\
\hline \multicolumn{5}{|l|}{$\begin{array}{l}\text { Com que intensidade você considera as seguintes afirmações caracterizações } \\
\text { da sua pessoa: }\end{array}$} \\
\hline 1. Eu sei onde encontrar a informação necessária para fazer uma compra. & & 0,93 & & \\
\hline $\begin{array}{l}\text { 2. Eu sei onde procurar para encontrar a informação do produto de que } \\
\text { preciso. }\end{array}$ & & 0,89 & & \\
\hline 3. Eu confio na minha habilidade em reconhecer uma marca valorizada. & & 0,91 & & \\
\hline 4. Eu confio no meu próprio julgamento, ao decidir quais marcas considerar. & & 0,94 & & \\
\hline 5. Eu muitas vezes me pergunto se fiz a correta seleção de compra. ${ }^{1}$ & & 0,87 & & \\
\hline $\begin{array}{l}\text { 6. Meus amigos ficam impressionados com a minha habilidade em fazer } \\
\text { compras satisfatórias. }\end{array}$ & & 0,90 & & \\
\hline 7. Eu impressiono as pessoas com as compras que faço. & & 0,87 & & \\
\hline 8. Eu posso dizer quando uma oferta tem "coisas por trás". & & 0,87 & & \\
\hline $\begin{array}{l}\text { 9. Eu posso perceber os truques de venda usados para fazer que os } \\
\text { consumidores comprem. }\end{array}$ & & 0,90 & & \\
\hline 10. Tenho receio de queixar-me ao gerente. ${ }^{1}$ & & 0,97 & & \\
\hline $\begin{array}{l}\text { 11. Eu não gosto de dizer ao vendedor que alguma coisa está errada numa } \\
\text { loja. }{ }^{1}\end{array}$ & & 0,88 & & \\
\hline
\end{tabular}

\footnotetext{
${ }^{1}$ Itens reversos.
} 